\title{
Juvenile primary fibromyalgia syndrome: A Review- Treatment and Prognosis
}

\author{
Maya Levy Coles ${ }^{1}$ and Yosef Uziel ${ }^{1,2^{*}}$ (D)
}

\begin{abstract}
Juvenile primary fibromyalgia syndrome (JPFS) is a chronic musculoskeletal pain syndrome affecting children and adolescents. In part one of this review, we discussed the epidemiology, etiology, pathogenesis, clinical manifestations and diagnosis of JPFS. Part two focuses on the treatment and prognosis of JPFS. Early intervention is important. The standard of care is multidisciplinary, combining various modalities-most importantly, exercise and cognitive behavioral therapy. Prognosis varies and symptoms may persist into adulthood.
\end{abstract}

Keywords: Fibromyalgia, Juvenile, JPFS, Chronic pain, Musculoskeletal pain syndrome

\section{Background}

Chronic musculoskeletal pain is a primary reason for referrals to pediatric rheumatologists [1]. It can be caused by a variety of inflammatory or non-inflammatory conditions, including arthritis, hypermobility, fibromyalgia (FM), growing pains and complex regional pain syndrome (CRPS) Amplified musculoskeletal pain syndrome is a generic, descriptive term used to describe chronic pain syndromes of unconfirmed etiology, such as FM, CRPS and idiopathic musculoskeletal pain. For individuals with this syndrome, pain signals are augmented; thus, mildly painful and nonpainful stimuli are registered by the body as very painful, which leads to attempts to avoid the induction of pain, leading to functional disability.

Our previous review focused on CRPS [2]. Yunus and Masi were the first to describe and use the term juvenile primary fibromyalgia syndrome (JPFS), in a clinical study published in 1985, in which they suggested diagnostic criteria based on 33 juveniles ages 17 years or younger, who suffered from chronic pain.

\footnotetext{
* Correspondence: uziely@zahav.net.il

${ }^{1}$ Department of Pediatrics, Meir Medical Center, Pediatric Rheumatology Unit, Kfar Saba, Israel

${ }^{2}$ Sackler School of Medicine, Tel Aviv University, Tel Aviv, Israel
}

JPFS is defined by chronic diffuse musculoskeletal aching and pain, which is the hallmark of this condition, and multiple predictable tender points. Part one of this review summarized the current information regarding the epidemiology, etiology, clinical manifestations and diagnosis of JPFS [3]. This part of the review focuses on treatment and prognosis.

\section{Treatment}

The primary goal in the treatment of JPFS is to enhance quality of life through pain relief and improved function. A multidisciplinary approach, combining behavioral and exercise-based modalities is currently the standard of care for JPFS $[4,5]$. Treatment should begin with nonpharmacologic modalities, most importantly exercise. Other non-pharmacologic modalities include movement and meditative treatments, and Cognitive Behavioral Therapy (CBT) [6]. Reassurance is very important, including acknowledging that the patient's pain is real, and emphasizing that it is not dangerous. Caregivers should communicate that although the pain may last for an unknown period and no immediate cure exists, there are therapeutic options that may reduce the pain over time. Setting goals of leading a full life, stressing the importance of lifestyle factors and treating emotional symptoms are critical. 
Multidisciplinary programs may be implemented in a hospital or outpatient setting. In a study comparing an intensive day-hospital rehabilitation program of physical, occupational and psychological therapies to outpatient treatment for children with significant pain-related disability, those enrolled in the day-hospital rehabilitation had significantly larger improvements in functional disability, pain-related fear, and readiness to change [7]. Intensive, multidisciplinary outpatient programs have also reported improved pain, function, and quality of life in children with JPFS [8].

A recent article suggested that the heterogeneity of the clinical presentation associated with FM, and the modest results, on average, for any therapy, call for a more individualized management strategy [9]. For example, The European League Against Rheumatism guidelines recommend a tailored approach directed by key FM symptoms of pain, sleep disorders, fatigue, functional disability [10].

\section{Physical therapy}

Exercise and physical therapy are main cornerstones in the treatment of all JPFS patients [11]. Benefits of exercise, which include mainly aerobic training, as well as strength/resistance training or movement-based therapies such as yoga and tai chi, have primarily been demonstrated in studies of FM treatment in adults [12-16]. Decreased pain and fatigue, and improvement in daily function and quality of life were noted.

The American Pain Society guidelines for children with FM recommend at least $30 \mathrm{~min}$ of moderate-tovigorous cardiovascular exercise two to 3 days a week [17].

Despite recommendations for exercise to manage juvenile FM pain, long-term exercise adherence in patients with FM is poor [18]. It has been demonstrated via actigraphy, that children with chronic pain are less physically active than their peers are [19]. Neurobiological alterations explain why exercise may be associated with increased short-term pain among patients with FM. However, various studies suggest that neurobiological changes associated with regular exercise have the potential to lead to long-term pain reduction, if FM patients can overcome the short-term increases in pain after exercise and avoid the increased fear of movement that discourages them from engaging in physical activity [20]. Most studies on exercise for FM are relatively short-term. Additional studies on long-term exercise programs are needed to determine whether adherence to exercise, as well as its benefits can be maintained over time.

A 2015 study by Sil et al. showed preliminary evidence of objective functional deficits in movement biomechanics (affecting gait, posture, balance, and movement), among adolescents with JPFS, as compared to their peers. These biomechanical alterations make them more prone to pain or injury during exercise, and may reinforce their activity avoidance [18].

Few exercise approaches and programs for the treatment of juvenile FM have been studied. In a small-scale, randomized, controlled trial of an exercise intervention in children with FM, Stephens et al. evaluated the feasibility and effectiveness of a 12-week aerobic exercise program versus qigong [21]. Both groups experienced improvement in FM symptoms and pain measures, but children in the aerobic training program exhibited greater improvements in fatigue, quality of life and physical functioning.

An interventional study investigated whether multidisciplinary treatment, including intensive exercise therapy would improve sleep quality in adolescents with JPFS. Although perceived sleep quality improved, objective measures did not [22].

Combined CBT and exercise-based interventions are often used clinically as part of multidisciplinary pain treatment programs. Despite its effectiveness in improving daily functioning and in coping with pain in adolescents with JPFS [23, 24], CBT did not independently result in increased physical activity, as was shown in a clinical trial via actigraphy monitoring [25]. Therefore, a multidisciplinary approach combining CBT and additional interventions to increase physical therapy is recommended.

An intervention combining CBT techniques with neuromuscular training: Fibromyalgia Integrative Training for Teens (FIT Teens), showed initial promise in adolescents with JPFS [26, 27]. Neuromuscular training, modified from evidence-based injury prevention protocols in pediatric sports medicine, is a tailored approach that targets biomechanical deficits in gait, posture, balance and movement, to reduce risks for injury or pain among patients with JPFS. Therefore, biomechanical assessment can be used to objectively demonstrate observable changes in performance after such an intervention [28]. A recent randomized, controlled, pilot study provided preliminary evidence that the FIT Teens intervention offers stronger treatment benefits than does CBT alone, particularly in reducing pain [29]. No additional randomized controlled trials of exercise interventions in juvenile FM were found.

It has been proposed that less strenuous forms of selfpaced physical activity and lifestyle modifications may lead to greater long-term adherence [30]. A recent study of adult women with FM demonstrated that substituting sedentary time with light or moderate-to-vigorous physical activity was associated with better quality of life and lower disease impact [31]. However, in a "Lifestyle Physical Activity" approach study in adults with FM, that 
consisted of strategies to increase incidental exercise throughout the day, beneficial effects were not sustained over time [32]. No similar studies using this approach were found in juvenile FM.

\section{Psychological therapy}

Psychological therapies, most prominently CBT), are the strongest evidence-based treatment modalities for JPFS. They are recommended as an integral part of the interdisciplinary treatment approach [4].

CBT techniques offer short-term, goal-oriented psychotherapy, emphasizing changes in thought patterns and behaviors. CBT has been found to be effective in reducing functional disability and in improving the ability to cope with pain among adolescents with JPFS.

An analysis of the results of 13 JPFS treatment programs using CBT alone or in combination with other treatment modalities, concluded that it provided worthwhile improvements in pain-related behavior, selfefficacy, coping strategies and overall physical function [33]. Sustained improvements in pain were most evident when individualized CBT was used.

Treatment programs for chronic pain typically take a rehabilitative approach. The initial emphasis is on decreasing pain-related disability, with the expectation that pain reduction will follow. A study that examined this hypothesis in youth with chronic pain, demonstrated a significant, rapid reduction in functional disability, as compared to pain reduction following CBT among youth with chronic pain [34].

In a multisite, single-blind, randomized, controlled clinical trial, CBT was compared to FM education for treating juvenile FM [23]. Patients (114 adolescents) in both groups had significant reductions in functional disability, pain, and symptoms of depression, but CBT was significantly superior to FM education in reducing functional disability. A subsequent study aimed to identify predictors for treatment response (reducing functional disability) at the 6-month follow-up, in the above clinical trial. Patients with greater initial functional disability and higher coping self-efficacy were significantly more likely to achieve a clinically significant improvement in functioning after CBT. Pain intensity, depressive symptoms, and parental pain history did not significantly predict treatment response [35].

The therapist is by necessity unblinded to the treatment as are the patients, who likely know when they are being treated with CBT. There is no such thing as a "placebo" for behavioral treatment. Hence, behavioral trials are usually "single-blind" studies in which the assessors are blinded and control groups are often "Attention-control" or "Education" comparison groups in which the active ingredients of treatment (e.g., CBT) are not delivered.
The effectiveness of psychotherapy has been demonstrated in many studies of pediatric patients with chronic pain. A 2018 Cochrane review, discussing psychological therapies for the management of chronic and recurrent pediatric pain [36], concluded that they might be effective for reducing pain frequency and intensity in children and adolescents with chronic pain conditions posttreatment, but not at follow-up. Psychological therapies were beneficial for reducing disability in children with mixed chronic pain conditions at post-treatment and at follow-up, and for children with headache at follow-up. No beneficial effect was found for improving depression or anxiety.

To address barriers to treatment access, such as distance and costs, technology (such as the Internet, computer-based programs, and smartphone applications) is being used to deliver psychological therapies remotely to children and adolescents with chronic pain. A 2019 Cochrane review [37] examined the efficacy of remotely-delivered psychological therapies for the management of chronic pediatric pain. They were found to reduce headache severity post-treatment. For the remaining outcomes, either no beneficial effect was found at post-treatment or follow-up, or evidence to determine an effect was lacking. Overall, participant satisfaction with treatment was positive. However, the quality of evidence was very low, and further studies are needed in this potentially promising field.

Studies have suggested a role or coping with pain and aspects of cognitive appraisal (psychological perceptions of pain) as potential psychological changes that explain CBT-related improvements among youth with juvenile FM [38]. Kashikar-Zuck et al. examined the psychological processes of CBT effectiveness in adolescents with juvenile FM [24]. CBT led to significant improvements in pain coping, catastrophizing, and coping efficacy, which were sustained over time. However, it was not found to mediate improvement in functional disability or depressive symptoms from post-treatment to 6month follow-up.

A significant number of FM patients suffer from comorbid psychiatric disorders, mainly anxiety and depression, and may benefit from referral to a psychiatrist. However, a subset of FM patients demonstrate strong emotional resilience despite their chronic symptoms and do not need psychiatric follow-up [6,39].

\section{Pharmacological treatments}

Currently, evidence for the efficacy of pharmaceuticals for the treatment of JPFS is limited. While several medications are approved by the US Food and Drug Administration (FDA) for the treatment of adults with FM (duloxetine, milnacipran and pregabalin), there are none for the treatment of juvenile FM [40, 41]. To our knowledge, no large- 
scale clinical trials of medications for JPFS are being conducted. Additional stringent, randomized controlled trials with longer follow-up periods are needed to determine the long-term efficacy and safety of medications for treating JPFS. Management of JPFS should include an emphasis on non-pharmacological approaches, although judicial use of medications may be considered for symptom management.

\section{Non-opioid analgesics and anti-inflammatory medications}

Topical analgesics, as well as oral over-the-counter analgesics, such as acetaminophen and non-steroidal antiinflammatory drugs, have been used to treat adult and juvenile FM, but they are not effective $[40,42]$. This is hypothesized to be due to their peripheral action, while the underlying pain mechanism in FM is centrally mediated [43]. Prednisone has not been found effective for adult FM [44].

\section{Anticonvulsants}

The gabapentinoids were originally used as antiepileptics, but are commonly prescribed for chronic pain. Studies of pregabalin and gabapentin for treatment of adult FM have demonstrated efficacy and good tolerability [45]. Pregabalin is FDA-approved for the treatment of adult FM [41] and is recommended in treatment guidelines for adult FM [10, 46, 47]. A singlecenter study that examined the potential benefit of a novel form of extended-release gabapentin for adult FM [48] demonstrated significant pain relief, but was limited by small sample size, short treatment duration (15 weeks) and lack of a control group. There is a paucity of evidence for the analgesic effect and safety of gabapentin and pregabalin in children and adolescents [49]. A double-blind, randomized, placebo-controlled trial from 2016 that examined the safety and efficacy of pregabalin in adolescents with FM, did not demonstrate clear efficacy, and had a slightly worse safety profile, as compared with adults [50].

\section{Anti-depressants}

Three main classes of anti-depressants are employed in the treatment of adult FM, with limited data supporting their use in the pediatric population. These include serotonin-norepinephrine reuptake inhibitors (SNRIs), Selective serotonin reuptake inhibitors (SSRIs), and tricyclic antidepressants.

SNRIs The two main SNRIs, duloxetine and milnacipran, are approved by the FDA, but not by the European Medical Agencies for the treatment of adult FM [51]. Current evidence on SNRIs for the treatment of FM in adults [51] suggests that duloxetine and milnacipran may provide a clinically relevant benefit over placebo in the frequency of pain relief. Limited data exist in the pediatric population. In a recent study in adolescents with JPFS, significantly more patients on duloxetine compared to placebo experienced decreased pain severity and there were no safety concerns [52]. Milnacipran was also assessed in JPFS [53]. The open-label phase of the study demonstrated improvement in pain and quality of life among those treated with milnacipran and it was well-tolerated. However, the study was terminated early due to low enrollment rates.

SSRIs Selective serotonin reuptake inhibitors (SSRIs) such as fluoxetine and paroxetine have had less convincing evidence for efficacy in adults with FM $[54,55]$. An exploratory, open-trial study of fluoxetine in juvenile FM demonstrated reduced pain and global improvement, but only low doses of the medication were tolerated, suggesting increased sensitivity of children to adverse effects [56].

Tricyclic antidepressants Amitriptyline is the tricyclic antidepressant prescribed for FM, based on studies limited to the adult population. In a randomized controlled trial that compared the effectiveness of naproxen versus amitriptyline for adults with FM, the latter was found to have a positive effect on various outcomes [42]. In a review from 2008, a beneficial therapeutic response was demonstrated after 6 to 8 weeks of treatment with 25 $\mathrm{mg} /$ day amitriptyline, but no effect was demonstrated when treated with a higher dose or for longer duration [57]. A systematic review from 2011 that compared the efficacy of amitriptyline, duloxetine and milnacipran, concluded that amitriptyline was superior in reducing pain, sleep disturbances and fatigue [58]. However, the validity of these findings is limited by low methodological quality and inconsistencies in data regarding adverse effects.

While there is little evidence supporting the use of anti-depressants for the treatment of JPFS, they have an important role in treating concomitant psychiatric conditions, such as anxiety and depression, that are common among children with FM [59,60]. The black box warning for increased suicidal tendency in young adults with major depressive disorder taking SSRIs should be carefully considered [61].

\section{Opioid analgesics}

Opioid analgesics are not effective for adult FM [62] and are not recommended in current adult FM treatment guidelines. Despite lack of evidence regarding the use of opioids for treating juvenile FM, opioid prescription for children doubled between 1990 and 2010 [63]; an alarming trend associated with adverse consequences. Accidental opioid poisoning in young children may lead to 
disability or death [64]. Use of opioid analgesics should be avoided in the treatment of JPFS, also due to the potential for dependency and abuse.

\section{Opiate receptor antagonists}

Studies have shown that low-dose naltrexone, an opiate receptor antagonist, may be effective, safe and inexpensive for adults FM [65]; yet, further large prospective controlled trials are needed before its use can be recommended for JPFS [66]. To our knowledge, no studies have been published regarding its use for the treatment of JPFS.

\section{Muscle relaxants}

Cyclobenzaprine, a muscle relaxant structurally similar to tricyclic antidepressants, is weakly recommended for treatment of FM in adults with sleep disturbances [10]. Further research is needed regarding the efficacy of a sublingual formulation of low-dose $(2.8 \mathrm{mg})$, slowrelease cyclobenzaprine, which may be better suited for children due to its decreased frequency of administration and non-tablet formulation [41].

\section{Medical Cannabis treatment}

Cannabinoids may be useful in the management of FM due to their effects on pain and associated symptoms [67]. Recent studies indicate a possible clinical advantage and safety of adjunctive medical cannabis treatment in adult FM patients [68]. In a prospective, observational study that assessed the effects of adding medical cannabis to the standard analgesic treatment of 102 adult FM patients [69], a significant improvement in FM outcome severity scales was observed in approximately $40 \%$, especially in those with sleep dysfunctions. A moderate improvement in the anxiety and depression scales was observed in $50 \%$ of patients, and one-third experienced mild adverse events. However, available evidence on medical cannabis in FM is very scarce, and no clinical trials were found regarding its use in pediatric FM patients. Further studies are needed to confirm current findings and to assess the efficacy and safety of medical cannabis in the pediatric population.

\section{Complementary medicine}

A significant number of adult patients use complementary treatments to relieve stress, pain, physical and psychological impairment [47], most of which have never been tried in children. Modalities include herbs, lotions, multivitamins, dietary interventions and mind-body interventions [70].

\section{Dietary interventions}

Various studies suggest an association between vitamin $\mathrm{D}$ deficiency and FM in adults, and a possible effect of vitamin D supplementation therapy in improving musculoskeletal symptoms, depression, and quality of life [71-73]. However, the causal relationship is inconclusive and conflicting results were obtained regarding the effect of vitamin D supplementation on symptom control. In a 2016 pilot study, children with musculoskeletal and orthopedic conditions, chronic or recurrent pain, and vitamin D deficiency were prescribed vitamin D replacement therapy for 6 months, with improvement in pain intensity and daily functioning [74]. Additional largescale randomized studies with JPFS patients are needed to validate these findings. Vitamin $D$ supplementation may be considered a co-adjuvant in JPFS therapy.

\section{Mind-body interventions}

A systematic review of complementary and alternative medicine for treating FM pain, concluded that balneotherapy and mind-body therapies showed the most promising findings [75].

Mindfulness meditation may affect pain variables in adolescents through its relation to pain catastrophizing [76]. A randomized, controlled pilot study of mindfulnessbased stress reduction for pediatric chronic pain, suggested increased mindfulness was effective, but showed inconsistent patterns with other outcome measures [77]. Self-reported outcomes after a mindfulness-based stress reduction intervention that included mindfulness and yoga for adults with FM, suggested potential benefits, but objective cardiac autonomic parameters did not $[78,79]$.

Randomized controlled trials of Tai Chi mind-body treatment for adults with FM demonstrated improvement in symptoms [80], and concluded that Tai Chi resulted in similar or greater improvement in various symptoms, as compared with aerobic exercise [81]. This mind-body approach may be considered a therapeutic option in the multidisciplinary management of FM. Further research on this modality for children and adolescents is needed.

\section{Acupuncture}

Acupuncture can be an effective adjuvant in the care of pediatric patients with chronic pain conditions, and may be clinically valuable in a multidisciplinary treatment program [82]. Studies of acupuncture in adults with FM exhibit conflicting results $[75,83,84]$. Therefore, additional studies are needed before this modality can be recommended for JPFS treatment.

\section{Guided imagery and hypnosis}

A systematic review and meta-analysis on guided imagery and hypnosis for fibromyalgia in adults [85], found it had a clinically relevant benefit in the outcomes of pain relief and psychological distress at the end of therapy, as compared with controls. Combined hypnosis 
with $\mathrm{CBT}$ was superior to $\mathrm{CBT}$ alone in reducing psychological distress at the end of therapy, but not in other outcomes.

\section{Nerve stimulation}

Transcutaneous Electrical Nerve Stimulation (TENS) is a noninvasive therapeutic method that uses low-voltage electrical current for pain relief, by activating endogenous pain inhibitory mechanisms [86]. The use of this modality for adult FM has been described in the literature [87]. It demonstrated significant improvements in movement-evoked pain, fatigue and other clinical outcomes [88]. There are currently no prospective, blinded studies of TENS use in juvenile FM, and further studies are needed to provide evidence of its efficacy in the pediatric population.

Studies suggest that non-invasive brain stimulation techniques, including repetitive transcranial magnetic stimulation and transcranial direct current stimulation, may be feasible and safe modalities as add-on treatments for adult FM [89]. They reduced pain levels and fatigue and improved daily functioning, with no serious adverse effects [90]. However, additional, substantially larger, studies of this modality are needed before applying it to children.

\section{Additional therapies}

Additional therapies studied in adults with FM include hyperbaric oxygen therapy [91, 92], occupational therapy [93] and climatotherapy [94]. They have not yet been studied in the pediatric population.

\section{Prognosis}

JPFS is likely to be a long-term condition for many patients. Initial studies indicated a positive prognosis, with improvement or resolution of symptoms over one to several years of follow-up [95-97]. However, more recent studies indicated a less favorable prognosis, demonstrating that physical and psychosocial symptoms of FM appear to be chronic in many patients [98, 99].

In a study by Connelly et al., children with JPFS exhibited worsening pain and quality of life over time, regardless of treatment modality or patient compliance with therapy [100]. In a follow-up study on long-term outcomes of youth with JPFS compared to healthy controls, $62.5 \%$ of participants in the JPFS group continued to experience widespread pain and $60.4 \%$ reported having all the cardinal features of FM at follow-up (range 2-6 years) [101]. In a similar prospective study, over $80 \%$ of patients continued to experience FM symptoms in early adulthood and $51.1 \%$ of the JPFS patients met the adult American College of Rheumatology criteria for FM [102]. Interestingly, in addition to physical and emotional impairment, the JPFS group did not achieve similar levels of education and fewer were married as compared to healthy control subjects of similar ages. In a summary of data on youth with JPFS, enrolled in the Childhood Arthritis and Rheumatology Research Alliance Legacy Registry, indicators of function and well-being were found to either worsen over time or remain relatively unchanged [103].

The effect of age at onset on prognosis is unclear. A study compared characteristics of children with JPFS onset at age 10 years or younger versus onset after age 10. After a mean follow-up of 14 months, there was no difference in outcomes between the groups [104]. However, since better outcomes were exhibited in children compared to adults, early detection of FM may indicate better prognosis [105].

While symptoms may be chronic, their severity may improve over time. In a recent prospective study [106], Kashikar-Zuck et al. examined longitudinal trajectories of pain and depressive symptoms in JPFS patients from adolescence to young adulthood, and the impact of these symptoms on physical functioning over time. At the 8year follow-up (mean age 24.2 years), most continued to suffer from pain and psychological impairment. However, steady improvement or rapid-rebounding improvement in pain severity was observed over time. Depressive symptoms improved, remained low-stable, or worsened over time, with the latter subgroup associated with poorer physical functioning over time. Consequently, JPFS patients with worsening depressive symptoms may require more intensive interventions to prevent long-term disability. The significant association of these symptoms with school absence, a risk factor for long-term consequences [107], including various psychiatric, economic, social and marital problems in adulthood [108] emphasizes the importance of addressing depressive and other psychiatric symptoms in adolescents with JPFS as well [59].

Cognitive factors such as catastrophizing and fear of movement have been shown to be poor prognostic factors in chronic pain conditions, including juvenile FM [24].

Family environment may affect JPFS prognosis. A controlled 4-year, follow-up study on the impact of family environment on the long-term adjustment of patients with JPFS, indicated that adolescents from controlling family environments are at increased risk for poorer emotional functioning in early adulthood [109]. Another study indicated low levels of resilience to noninflammatory chronic musculoskeletal pain syndrome in adolescent patients and their parents, with a negative effect on symptoms [110]. Therefore, behavioral and family interventions should foster independent coping among adolescents with JPFS and greater parental flexibility, to enhance successful long-term emotional functioning. Social support is a predictor of function and 
symptoms in adolescents with JPFS, as well [111]. Medical caregivers may experience difficulties and frustration when dealing with teenage patients who remain dysfunctional over time, despite their interventions.

Additional prospective research is needed to determine the long-term prognosis of juvenile FM patients and implications for treatment.

\section{Conclusions}

Juvenile primary FM syndrome is a chronic, musculoskeletal pain syndrome. Standard care consists of a multidisciplinary approach. Physical exercise in conjunction with psychological treatment comprise the mainstay of therapy. Management should rely on non-pharmacological approaches, but judicial use of medications may be considered for symptom management. The treatment plan should be individually tailored, taking into consideration the child's environment, including familial, social and academic components. Data regarding the prognosis of JPFS conflict, and it may be a long-term condition for many patients. Additional high-quality studies are needed to deepen understanding of etiologic factors, develop better diagnostic tools, and verify effective treatment programs for the pediatric population, with the goals of early detection, improved treatment outcomes and better long-term prognosis.

\section{Abbreviations}

CBT: Cognitive behavioral therapy; CRPS: Complex regional pain syndrome; FDA: United States. food and drug administration; FIT Teens: Fibromyalgia integrative training for teens; FM: Fibromyalgia; JPFS: Juvenile primary fibromyalgia syndrome; SNRIs: Serotonin norepinephrine reuptake inhibitors; SSRIs: Selective serotonin reuptake inhibitors; TENS: Transcutaneous electrical nerve stimulation

\section{Acknowledgments}

We thank Faye Schreiber, MS for editing the manuscript.

\section{Authors' contributions}

MLC participated in the literature review and in writing the manuscript. YU participated in the literature review and in writing the manuscript. The author(s) read and approved the final manuscript.

\section{Funding}

The study was not funded.

\section{Availability of data and materials}

Data sharing is not applicable to this article as no datasets were generated or analyzed during the current study.

\section{Declarations}

Ethics approval and consent to participate

Not applicable.

\section{Consent for publication}

Not applicable.

\section{Competing interests}

The authors declare that they have no competing interests.
Received: 18 February 2021 Accepted: 10 March 2021

Published online: 18 May 2021

\section{References}

1. Weiss JE, Stinson JN. Pediatric pain syndromes and noninflammatory musculoskeletal pain. Pediatr Clin North Am. 2018;65(4):801-26. Available from:. https://doi.org/10.1016/j.pcl.2018.04.004.

2. Weissmann R, Uziel Y. Pediatric complex regional pain syndrome: a review. Pediatr Rheumatol Online J. 2016;14(1):29. https://doi.org/10.1186/s12969-01 6-0090-8.

3. Levy Coles $M$, Weissmann $R$, Uziel $Y$. Juvenile primary fibromyalgia syndrome: a review - epidemiology, etiology, pathogenesis, clinical manifestations and diagnosis. Pediatr Rheumatol Online J. 2021;19(1):22. https://doi.org/10.1186/s12969-021-00493-6.

4. Gmuca S, Sherry DD. Fibromyalgia: treating pain in the juvenile patient. Pediatr Drugs. 2017;19(4):325-38. https://doi.org/10.1007/s40272-017-0233-5.

5. Tesher MS. Juvenile fibromyalgia: a multidisciplinary approach to treatment. Pediatr Ann. 2015;44(6):e136-41 Available from: http://www.healio.com/ doiresolver?doi=10.3928/00904481-20150611-08.

6. Ablin JN. Fibromyalgia 2019: myths and realities. Isr Med Assoc J. 2019;21(6): 426-8 Available from: http://www.ncbi.nlm.nih.gov/pubmed/31280518.

7. Simons LE, Sieberg CB, Pielech M, Conroy C, Logan DE. What does it take? Comparing intensive rehabilitation to outpatient treatment for children with significant Pain-related disability. J Pediatr Psychol. 2013;38(2):213-23 Available from: https://academic.oup.com/jpepsy/article-lookup/doi/10.1093/ jpepsy/jss109.

8. Sherry DD, Brake L, Tress JL, Sherker J, Fash K, Ferry K, Weiss PF. The treatment of juvenile fibromyalgia with an intensive physical and psychosocial program. J Pediatr. 2015;167(3):731-7. Available from:. https:// doi.org/10.1016/j.jpeds.2015.06.036.

9. Häuser W, Perrot S, Clauw DJ, Fitzcharles M-A. Unravelling fibromyalgia_steps toward individualized management. J Pain. 2018;19(2): 125-34. Available from: https://linkinghub.elsevier.com/retrieve/pii/S152 6590017307009. https://doi.org/10.1016/j.jpain.2017.08.009.

10. Macfarlane GJ, Kronisch C, Dean LE, Atzeni F, Häuser W, Fluß E, Choy E, Kosek E, Amris K, Branco J, Dincer F, Leino-Arjas P, Longley K, McCarthy GM, Makri S, Perrot S, Sarzi-Puttini P, Taylor A, Jones GT. EULAR revised recommendations for the management of fibromyalgia. Ann Rheum Dis. 2017;76(2):318-28 Available from: http://ard.bmj.com/lookup/doi/10.1136/a nnrheumdis-2016-209724.

11. Sherry DD. Paediatric rheumatic disease: physical activity levels in the treatment of juvenile fibromyalgia. Nat Rev Rheumatol. 2013;9(1):8-9. Available from:. https://doi.org/10.1038/nrrheum.2012.193.

12. Jones KD, Adams D, Winters-Stone K, Burckhardt CS. A comprehensive review of 46 exercise treatment studies in fibromyalgia (1988-2005). Health Qual Life Outcomes. 2006;4:67 Available from: http://www.ncbi.nlm.nih.gov/ pubmed/16999856.

13. Mist S, Firestone K, Jones KD. Complementary and alternative exercise for fibromyalgia: a meta-analysis. J Pain Res. 2013;6:247-60. Available from: http://www.dovepress.com/complementary-and-alternative-exercise-forfibromyalgia-a-meta-analysi-peer-reviewed-article-JPR.

14. Ericsson A, Palstam A, Larsson A, Löfgren M, Bileviciute-Ljungar I, Bjersing J, et al. Resistance exercise improves physical fatigue in women with fibromyalgia: a randomized controlled trial. Arthritis Res Ther. 2016;18(1):176 Available from: http://arthritis-research.biomedcentral.com/articles/10.1186/ s13075-016-1073-3.

15. Hooten MW, Qu W, Townsend CO, Judd JW. Effects of strength vs aerobic exercise on pain severity in adults with fibromyalgia: a randomized equivalence trial. Pain. 2012;153(4):915-23. Available from: http://content. wkhealth.com/linkback/openurl?sid=WKPTLP:landingpage\&an=00006396-2 01204000-00027. https://doi.org/10.1016/j.pain.2012.01.020.

16. Bidonde J, Busch AJ, Schachter CL, Overend TJ, Kim SY, Góes SM, et al. Aerobic exercise training for adults with fibromyalgia. Cochrane Database Syst Rev. 2017; Available from. https://doi.org/10.1002/14651858.CD012700.

17. Buckhardt CS, Goldenberg D, Crofford L, Gerwin R, Gowens S, Jackson K, Kugel P, McCarberg W, Rudin NSL, Taylor AG, Taylor JTD. Guideline for the management of fibromyalgia syndrome pain in adults and children. Glenview Am Pain Soc (APS); (Clinical Pract Guidel no 4). 2005:4:109 Available from: http://teamworkstherapy.com/pdf/APS\%20guideline-\%2 OFibromyalgia.pdf. 
18. Sil S, Thomas S, DiCesare C, Strotman D, Ting TV, Myer G, et al. Preliminary evidence of altered biomechanics in adolescents with juvenile fibromyalgia. Arthritis Care Res (Hoboken). 2015;67(1):102-11. Available from:. https://doi. org/10.1002/acr.22450.

19. Wilson AC, Palermo TM. Physical activity and function in adolescents with chronic pain: a controlled study using actigraphy. J Pain [Internet]. 2012; 13(2):121-30. Available from: https://linkinghub.elsevier.com/retrieve/pii/S1 526590011007413. https://doi.org/10.1016/j.jpain.2011.08.008.

20. Black WR, Kashikar-Zuck S. Exercise interventions for juvenile fibromyalgia: current state and recent advancements. Pain Manag. 2017;7(3):143-8. https://doi.org/10.2217/pmt-2016-0066.

21. Stephens S, Feldman BM, Bradley N, Schneiderman J, Wright V, SinghGrewal D, Lefebvre A, Benseler SM, Cameron B, Laxer R, O'brien C, Schneider R, Silverman E, Spiegel L, Stinson J, Tyrrell PN, Whitney K, Tse SML. Feasibility and effectiveness of an aerobic exercise program in children with fibromyalgia: results of a randomized controlled pilot trial. Arthritis Care Res. 2008;59(10):1399-406. https://doi.org/10.1002/art.24115.

22. Olsen MN, Sherry DD, Boyne K, McCue R, Gallagher PR, Brooks LJ. Relationship between sleep and pain in adolescents with juvenile primary fibromyalgia syndrome. Sleep. 2013;36(4):509-16. Available from: https://aca demic.oup.com/sleep/article/36/4/509/2595956. https://doi.org/10.5665/ sleep.2534.

23. Kashikar-zuck S, Ting TV, Arnold LM, Bean J, Powers SW, Graham TB, et al. Cognitive-behavioral therapy for the treatment of juvenile Fibromyalgia. Arthritis Rheum. 2012;64(1):297-305. https://doi.org/10.1002/art.30644.

24. Kashikar-Zuck S, Sil S, Lynch-Jordan AM, Ting TV, Peugh J, Schikler KN, et al. Changes in pain coping, catastrophizing, and coping efficacy after cognitive-behavioral therapy in children and adolescents with juvenile fibromyalgia. J Pain. 2013;14(5):492-501 Available from: https://linkinghub. elsevier.com/retrieve/pii/S1526590013000345.

25. Kashikar-Zuck S, Flowers SR, Strotman D, Sil S, Ting TV, Schikler KN. Physical activity monitoring in adolescents with juvenile fibromyalgia: findings from a clinical trial of cognitive-behavioral therapy. Arthritis Care Res (Hoboken). 2013;65(3):398-405. https://doi.org/10.1002/acr.21849.

26. Thomas SM, Sil S, Kashikar-Zuck S, Myer GD. Can modified neuromuscular training support the treatment of chronic pain in adolescents? Strength Cond J. 2013;35(3):12-26. Available from: https://insights.ovid.com/crossref?an=0012654 8-201306000-00003. https://doi.org/10.1519/SSC.0b013e31829206c1.

27. Kashikar-Zuck S, Tran ST, Barnett K, Bromberg MH, Strotman D, Sil S, Thomas SM, Joffe N, Ting TV, Williams SE, Myer GD. A qualitative examination of a new combined cognitive-behavioral and neuromuscular training intervention for juvenile fibromyalgia. Clin J Pain. 2016;32(1):70-81. Available from: http://content.wkhealth.com/linkback/openurl?sid=WKPTLP:landingpa ge\&an=00002508-201601000-00009. https://doi.org/10.1097/AJP. 0000000000000221.

28. Tran ST, Thomas S, DiCesare C, Pfeiffer M, Sil S, Ting TV, et al. A pilot study of biomechanical assessment before and after an integrative training program for adolescents with juvenile fibromyalgia. Pediatr Rheumatol. 2016;14(1):1-10. Available from:. https://doi.org/10.1186/s12969-016-0103-7.

29. Kashikar-Zuck S, Black WR, Pfeiffer M, Peugh J, Williams SE, Ting TV, et al. Pilot randomized trial of integrated cognitive-behavioral therapy and neuromuscular training for juvenile fibromyalgia: the FIT Teens Program. J Pain. 2018;19(9):1049-62. Available from:. https://doi.org/10.1016/j.jpain.2018.04.003.

30. Williams DM, Dunsiger S, Emerson JA, Gwaltney CJ, Monti PM, Miranda R. Self-paced exercise, affective response, and exercise adherence: a preliminary investigation using ecological momentary assessment. J Sport Exerc Psychol. 2016;38(3):282-91. Available from: https://journals.huma nkinetics.com/view/journals/jsep/38/3/article-p282.xml. https://doi.org/1 0.1123/jsep.2015-0232.

31. Gavilán-Carrera B, Segura-Jiménez V, Mekary RA, Borges-Cosic M, AcostaManzano P, Estévez-López F, Álvarez-Gallardo IC, Geenen R, DelgadoFernández M. Substituting sedentary time with physical activity in fibromyalgia and the association with quality of life and impact of the disease: the al-Ándalus project. Arthritis Care Res (Hoboken). 2019;71(2):2819 Available from: https://onlinelibrary.wiley.com/doi/abs/10.1002/acr.23717.

32. Fontaine KR, Conn L, Clauw DJ. Effects of lifestyle physical activity in adults with fibromyalgia. J Clin Rheumatol. 2011;17(2):64-8. Available from: http://content.wkhealth.com/linkback/openurl?sid=WKPTLP:landingpa ge\&an=00124743-201103000-00003. https://doi.org/10.1097/RHU.0b013 e31820e7ea7.
33. Bennett R, Nelson D. Cognitive behavioral therapy for fibromyalgia. Nat Clin Pract Rheumatol. 2006;2(8):416-24. Available from: http://www.nature.com/a rticles/ncprheum0245. https://doi.org/10.1038/ncprheum0245.

34. Lynch-Jordan AM, Sil S, Peugh J, Cunningham N, Kashikar-Zuck S, Goldschneider KR. Differential changes in functional disability and pain intensity over the course of psychological treatment for children with chronic pain. Pain. 2014;155(10):1955-61. Available from: http://insights.ovid. com/crossref?an=00006396-201410000-00012. https://doi.org/10.1016/j.pa in.2014.06.008.

35. Sil S, Arnold LM, Lynch-Jordan A, Ting TV, Peugh J, Cunningham N, Powers SW, Lovell DJ, Hashkes PJ, Passo M, Schikler KN, Kashikar-Zuck S. Identifying treatment responders and predictors of improvement after cognitivebehavioral therapy for juvenile fibromyalgia. Pain. 2014;155(7):1206-12. https://doi.org/10.1016/j.pain.2014.03.005.

36. Fisher E, Law E, Dudeney J, Palermo TM, Stewart G, Eccleston C. Psychological therapies for the management of chronic and recurrent pain in children and adolescents. Cochrane Database Syst Rev. 2018; Available from:. https://doi.org/10.1002/14651858.CD003968.pub5.

37. Fisher E, Law E, Dudeney J, Eccleston C, Palermo TM. Psychological therapies (remotely delivered) for the management of chronic and recurrent pain in children and adolescents. Cochrane Database Syst Rev. 2019;2019(4);4.

38. Sil S, Kashikar-Zuck S. Understanding why cognitive-behavioral therapy is an effective treatment for adolescents with juvenile fibromyalgia. Int J Clin Rheumtol. 2013;8(2):213-9. https://doi.org/10.2217/ijr.13.3.

39. Hassett AL, Simonelli LE, Radvanski DC, Buyske S, Savage SV, Sigal LH. The relationship between affect balance style and clinical outcomes in fibromyalgia. Arthritis Rheum. 2008;59(6):833-40. Available from:. https://doi. org/10.1002/art.23708

40. Buskila D, Ablin JN. Treating juvenile fibromyalgia: cognitive-behavioral therapy, exercise and pharmacotherapy. Pain Manag. 2013;3(5):323-4. https://doi.org/10.2217/pmt.13.37.

41. Calandre EP, Rico-Villademoros F, Slim M. An update on pharmacotherapy for the treatment of fibromyalgia. Expert Opin Pharmacother. 2015;16(9): 1347-68 Available from: http://www.tandfonline.com/doi/full/10.1517/14 656566.2015.1047343.

42. Goldenberg DL, Felson DT, Dinerman H. A randomized, controlled trial of amitriptyline and naproxen in the treatment of patients with fibromyalgia. Arthritis Rheum. 1986;29(11):1371-7. Available from:. https://doi.org/10.1 002/art.1780291110

43. Hoffart CM, Wallace DP. Amplified pain syndromes in children: treatment and new insights into disease pathogenesis. Curr Opin Rheumatol. 2014; 26(5):592-603 Available from: http://www.ncbi.nlm.nih.gov/pubmed/2501 0441. [cited 2019 Oct 15].

44. Clark S, Tindall E, Bennett RM. A double blind crossover trial of prednisone versus placebo in the treatment of fibrositis. J Rheumatol. 1985;12(5):980-3 Available from: http://www.ncbi.nlm.nih.gov/pubmed/3910836.

45. Arnold LM, Goldenberg DL, Stanford SB, Lalonde JK, Sandhu HS, Keck PE, Welge JA, Bishop F, Stanford KE, Hess EV, Hudson Jl. Gabapentin in the treatment of fibromyalgia: a randomized, double-blind, placebo-controlled, multicenter trial. Arthritis Rheum. 2007;56(4):1336-44. Available from:. https://doi.org/10.1002/art.22457.

46. Fitzcharles M-A, Ste-Marie PA, Goldenberg DL, Pereira JX, Abbey S, Choinière M, Ko G, Moulin DE, Panopalis P, Proulx J, Shir Y, the National Fibromyalgia Guideline Advisory Panel. 2012 Canadian guidelines for the diagnosis and management of fibromyalgia syndrome: executive summary. Pain Res Manag. 2013;18(3):119-26. Available from: http://www.hindawi.com/journa Is/prm/2013/918216/. https://doi.org/10.1155/2013/918216.

47. Ablin J, Fitzcharles M-A, Buskila D, Shir Y, Sommer C, Häuser W. Treatment of fibromyalgia syndrome: recommendations of recent evidence-based interdisciplinary guidelines with special emphasis on complementary and alternative therapies. Evidence-Based Complement Altern Med. 2013;2013:17 Available from: http://www.hindawi.com/journals/ecam/2013/485272/.

48. North JM, Hong KJ, Rauck RL. The effect of a novel form of extendedrelease gabapentin on pain and sleep in fibromyalgia subjects: an openlabel pilot study. Pain Pract [Internet]. 2016;16(6):720-9. Available from:. https://doi.org/10.1111/papr.12319.

49. Egunsola O, Wylie CE, Chitty KM, Buckley NA. Systematic review of the efficacy and safety of gabapentin and pregabalin for pain in children and adolescents. Anesth Analg. 2019;128(4):811-9. Available from: http://insights. 
ovid.com/crossref?an=00000539-201904000-00027. https://doi.org/10.1213/A NE.00000000000003936.

50. Arnold LM, Schikler KN, Bateman L, Khan T, Pauer L, Bhadra-Brown P, et al. Safety and efficacy of pregabalin in adolescents with fibromyalgia: a randomized, double-blind, placebo-controlled trial and a 6-month openlabel extension study. Pediatr Rheumatol. 2016;14(1):46 Available from: http://ped-rheum.biomedcentral.com/articles/10.1186/s12969-016-0106-4.

51. Welsch P, Üçeyler N, Klose P, Walitt B, Häuser W. Serotonin and noradrenaline reuptake inhibitors (SNRIs) for fibromyalgia. Cochrane Database Syst Rev. 2018 ; Available from:. https://doi.org/10.1002/14651858. CD010292.pub2.

52. Upadhyaya HP, Arnold LM, Alaka K, Qiao M, Williams D, Mehta R. Efficacy and safety of duloxetine versus placebo in adolescents with juvenile fibromyalgia: results from a randomized controlled trial. Pediatr Rheumatol. 2019;17(1):1-10

53. Arnold LM, Bateman L, Palmer RH, Lin Y. Preliminary experience using milnacipran in patients with juvenile fibromyalgia: lessons from a clinical trial program. Pediatr Rheumatol. 2015;13(1):1-14. Available from:. https:// doi.org/10.1186/s12969-015-0025-9.

54. Patkar AA, Masand PS, Krulewicz S, Mannelli P, Peindl K, Beebe KL, Jiang W. A randomized, controlled, trial of controlled release paroxetine in fibromyalgia. Am J Med. 2007;120(5):448-54. Available from: https:// linkinghub.elsevier.com/retrieve/pii/S0002934306006851. https://doi.org/10.1 016/j.amjmed.2006.06.006.

55. Wolfe F, Cathey MA, Hawley DJ. A double-blind placebo controlled trial of fluoxetine in fibromyalgia. Scand J Rheumatol. 1994;23(5):255-9 Available from: http://www.tandfonline.com/doi/full/10.3109/03009749409103725.

56. Mariutto EN, Stanford SB, Kashikar-Zuck S, Welge JA, Arnold LM. An exploratory, open trial of fluoxetine treatment of juvenile fibromyalgia. J Clin Psychopharmacol. 2012;32(2):293-5. https://doi.org/10.1097/JCP.0b013e31824 858dc.

57. Nishishinya B, Urrutia G, Walitt B, Rodriguez A, Bonfill X, Alegre C, Darko G. Amitriptyline in the treatment of fibromyalgia: a systematic review of its efficacy. Rheumatology. 2008:47(12):1741-6 Available from: https://academic oup.com/rheumatology/article-lookup/doi/10.1093/rheumatology/ken317.

58. Hauser W, Petzke F, Uceyler N, Sommer C. Comparative efficacy and acceptability of amitriptyline, duloxetine and milnacipran in fibromyalgia syndrome: a systematic review with meta-analysis. Rheumatology. 2011; 50(3):532-43 Available from: https://academic.oup.com/rheumatology/a rticle-lookup/doi/10.1093/rheumatology/keq354.

59. Cunningham NR, Tran ST, Lynch-Jordan AM, Ting TV, Sil S, Strotman D, et al. Psychiatric disorders in young adults diagnosed with juvenile fibromyalgia in adolescence. J Rheumatol. 2015;42(12):2427-33 Available from: http:// www.jrheum.org/lookup/doi/10.3899/jheum.141369.

60. Kashikar-Zuck S, Parkins IS, Graham TB, Lynch AM, Passo M, Johnston M, Schikler KN, Hashkes PJ, Banez G, Richards MM. Anxiety, mood, and behavioral disorders among pediatric patients with juvenile fibromyalgia syndrome. Clin J Pain. 2008;24(7):620-6. Available from: https://insights.ovid. com/crossref?an=00002508-200809000-00009. https://doi.org/10.1097/AJP. 0b013e31816d7d23.

61. Walitt B, Urrútia G, Nishishinya MB, Cantrell SE, Häuser W. Selective serotonin reuptake inhibitors for fibromyalgia syndrome. Cochrane Database Syst Rev. 2015; Available from:. https://doi.org/10.1002/14651858.CD011735.

62. Ngian G-S, Guymer EK, Littlejohn GO. The use of opioids in fibromyalgia. Int J Rheum Dis. 2011;14(1):6-11. Available from:. https://doi.org/10.1111/j.1 756-185X.2010.01567.X.

63. Schechter NL. Pediatric pain management and opioids. JAMA Pediatr. 2014; 168(11):987 Available from: http://archpedi.jamanetwork.com/article.a spx?doi=10.1001/jamapediatrics.2014.1441.

64. Bailey JE, Campagna E, Dart RC. The underrecognized toll of prescription opioid abuse on young children. Ann Emerg Med. 2009;53(4):419-24. Available from: https://linkinghub.elsevier.com/retrieve/pii/S019606440801 5035. https://doi.org/10.1016/j.annemergmed.2008.07.015.

65. Metyas SK, Chen CL, Yeter K, Solyman J, Arkfeld D. Low dose naltrexone in the treatment of fibromyalgia. Curr Rheumatol Rev. 2018;14(2):177-80. Available from: http://www.eurekaselect.com/151058/article. https://doi. org/10.2174/1573397113666170321120329.

66. Trofimovitch D, Baumrucker SJ. Pharmacology update: low-dose naltrexone as a possible nonopioid modality for some chronic, nonmalignant pain syndromes. Am J Hosp Palliat Med. 2019;36(10):907-12 Available from: http://journals.sagepub.com/doi/10.1177/1049909119838974.
67. Sarzi-Puttini P, Ablin J, Trabelsi A, Fitzcharles M-A, Marotto D, Häuser W. Cannabinoids in the treatment of rheumatic diseases: pros and cons. Autoimmun Rev. 2019;18(12):102409 Available from: https://inkinghub. elsevier.com/retrieve/pii/S1568997219302162.

68. Sagy I, Bar-Lev Schleider L, Abu-Shakra M, Novack V. Safety and efficacy of medical cannabis in fibromyalgia. J Clin Med. 2019;8(6):807 Available from: https://www.mdpi.com/2077-0383/8/6/807.

69. Giorgi V, Bongiovanni S, Atzeni F, Marotto D, Salaffi F, Sarzi-Puttini P. Adding medical cannabis to standard analgesic treatment for fibromyalgia: a prospective observational study. Clin Exp Rheumatol. 2020;38(1):53-9 Available from: http://www.ncbi.nlm.nih.gov/pubmed/32116208.

70. Patkar AA, Bilal L, Masand PS. Management of fibromyalgia. Curr Psychiatry Rep. 2003;5(3):218-24 Available from: http://www.ncbi.nlm.nih.gov/ pubmed/12773276.

71. Yilmaz R, Salli A, Cingoz HT, Kucuksen S, Ugurlu H. Efficacy of vitamin D replacement therapy on patients with chronic nonspecific widespread musculoskeletal pain with vitamin D deficiency. Int J Rheum Dis. 2016; 19(12):1255-62. Available from:. https://doi.org/10.1111/1756-185X.12960.

72. Ellis SD, Kelly ST, Shurlock JH, ALN H. The role of vitamin D testing and replacement in fibromyalgia: a systematic literature review. BMC Rheumatol. 2018;2(1):28 Available from: https://bmcrheumatol.biomedcentral.com/a rticles/10.1186/s41927-018-0035-6.

73. Martins YA, Cardinali CAEF, Ravanelli MI, Brunaldi K. Is hypovitaminosis D associated with fibromyalgia? A systematic review. Nutr Rev. 2019:78;11533. Available from: http://www.ncbi.nlm.nih.gov/pubmed/31397485.

74. Blagojevic Z, Nikolic V, Kisic-Tepavcevic D, Terzic Supic Z, Kovacevic R, Zivkovic $Z$, et al. Musculoskeletal pain and vitamin D deficiency in children: a pilot follow-up study of vitamin $\mathrm{D}$ therapy in musculoskeletal/orthopedic conditions. Acta Chir Orthop Traumatol Cech. 2016;83(1):21-6 Available from: http://www.ncbi.nlm.nih.gov/pubmed/26936061.

75. Terhorst L, Schneider MJ, Kim KH, Goozdich LM, Stilley CS. Complementary and alternative medicine in the treatment of pain in fibromyalgia: a systematic review of randomized controlled trials. J Manipulative Physiol Ther. 2011;34(7):483-96. Available from: https://linkinghub.elsevier.com/ retrieve/pii/S0161475411000959. https://doi.org/10.1016/j.jmpt.2011.05.006.

76. Petter M, Chambers CT, McGrath PJ, Dick BD. The role of trait mindfulness in the pain experience of adolescents. J Pain. 2013;14(12):1709-18. Available from: https://linkinghub.elsevier.com/retrieve/pii/S152659001301239X. https://doi.org/10.1016/j.jpain.2013.08.015.

77. Jastrowski Mano KE, Salamon KS, Hainsworth KR, Anderson Khan K, Ladwig RJ, Davies WH, et al. A randomized, controlled pilot study of mindfulness-based stress reduction for pediatric chronic pain. Altern Ther Health Med. 2013;19(6):8-14 Available from: http://www.ncbi.nlm. nih.gov/pubmed/24254033.

78. Schmidt S, Grossman P, Schwarzer B, Jena S, Naumann J, Walach H. Treating fibromyalgia with mindfulness-based stress reduction: results from a 3armed randomized controlled trial 2 . Pain. 2011;152(2):361-9. Available from: http://content.wkhealth.com/linkback/openurl?sid=WKPTLP:landingpa ge\&an=00006396-201102000-00022. https://doi.org/10.1016/j.pain.2010.10. 043.

79. Grossman P, Deuring G, Walach H, Schwarzer B, Schmidt S. Mindfulnessbased intervention does not influence cardiac autonomic control or the pattern of physical activity in fibromyalgia during daily life. Clin J Pain. 2017; 33(5):385-94. Available from: http://insights.ovid.com/crossref?an=00002 508-201705000-00001. https://doi.org/10.1097/AJP.0000000000000420.

80. Wang C, Schmid CH, Rones R, Kalish R, Yinh J, Goldenberg DL, Lee Y, McAlindon T. A randomized trial of tai chi for fibromyalgia. N Engl J Med. 2010;363(8):743-54 Available from: http://www.nejm.org/doi/abs/10.1056/ NEJMoa0912611.

81. Wang C, Schmid CH, Fielding RA, Harvey WF, Reid KF, Price LL, et al. Effect of tai chi versus aerobic exercise for fibromyalgia: comparative effectiveness randomized controlled trial. BMJ. 2018 ;k851. Available from: http://www. bmj.com/lookup/doi/10.1136/bmj.k851

82. Golianu B, Yeh A, Brooks M. Acupuncture for pediatric pain. Children. 2014; 1(2):134-48. https://doi.org/10.3390/children1020134.

83. Deare JC, Zheng Z, Xue CC, Liu JP, Shang J, Scott SW, et al. Acupuncture for treating fibromyalgia. Cochrane Database Syst Rev. 20131; Available from:. https://doi.org/10.1002/14651858.CD007070.pub2.

84. Langhorst J, Klose P, Musial F, Irnich D, Häuser W. Efficacy of acupuncture in fibromyalgia syndrome - a systematic review with a meta-analysis of controlled clinical trials. Rheumatology. 2010;49(4):778-88 Available from: 
https://academic.oup.com/rheumatology/article-lookup/doi/10.1093/rheuma tology/kep439.

85. Zech N, Hansen E, Bernardy K, Häuser W. Efficacy, acceptability and safety of guided imagery/hypnosis in fibromyalgia - a systematic review and metaanalysis of randomized controlled trials. Eur J Pain. 2017;21(2):217-27. Available from:. https://doi.org/10.1002/ejp.933.

86. DeSantana JM, Walsh DM, Vance C, Rakel BA, Sluka KA. Effectiveness of transcutaneous electrical nerve stimulation for treatment of hyperalgesia and pain. Curr Rheumatol Rep. 2008;10(6):492-9 Available from: http://www. ncbi.nlm.nih.gov/pubmed/19007541.

87. Honda Y, Sakamoto J, Hamaue Y, Kataoka H, Kondo Y, Sasabe R, et al. Effects of physical-agent pain relief modalities for fibromyalgia patients: a systematic review and meta-analysis of randomized controlled trials. Pain Res Manag. 2018;2018:1-9 Available from: https://www.hindawi.com/journa Is/prm/2018/2930632/.

88. Dailey DL, Vance CG, Rakel BA, Zimmerman MB, Embree J, Merriwether EN et al. A randomized controlled trial of TENS for Movement-Evoked Pain In Women With Fibromyalgia. Arthritis Rheumatol. 2019:art.41170 Available from: https://onlinelibrary.wiley.com/doi/abs/10.1002/art.41170.

89. Hou W-H, Wang T-Y, Kang J-H. The effects of add-on non-invasive brain stimulation in fibromyalgia: a meta-analysis and meta-regression of randomized controlled trials. Rheumatology. 2016;55(8):1507-17 Available from: https://academic.oup.com/rheumatology/article-lookup/doi/10.1093/ rheumatology/kew205.

90. Fitzgibbon BM, Hoy KE, Knox LA, Guymer EK, Littlejohn G, Elliot D, Wambeek LE, McQueen S, Elford KA, Lee SJ, Enticott PG, Fitzgerald PB. Evidence for the improvement of fatigue in fibromyalgia: a 4-week left dorsolateral prefrontal cortex repetitive transcranial magnetic stimulation randomizedcontrolled trial. Eur J Pain. 2018;22(7):1255-67. Available from:. https://doi. org/10.1002/ejp.1213.

91. Efrati S, Golan H, Bechor Y, Faran Y, Daphna-Tekoah S, Sekler G, et al. Hyperbaric oxygen therapy can diminish fibromyalgia syndrome prospective clinical trial. Cordero MD, editor. PLoS One. 2015;10(5):e0127012 Available from: https://dx.plos.org/10.1371/journal.pone.0127012.

92. Atzeni F, Masala I, Cirillo M, Boccassini L, Sorbara S, Alciati A. Hyperbaric oxygen therapy in fibromyalgia and the diseases involving the central nervous system. Clin Exp Rheumatol. 2020;38(123):0094-8 Available from: https://www-clinexprheumatol-org.meir-ez.medlcp.tau.ac.il/abstra ct.asp?a=14838.

93. Yavne $Y$, Kabaha A, Rosen $T$, Avisar I, Orbach H, Amital D, et al. The powers of flowers: evaluating the impact of floral therapy on pain and psychiatric symptoms in fibromyalgia. Isr Med Assoc J. 2019;21(7):449-53 Available from: http://www.ncbi.n/m.nih.gov/pubmed/31507119.

94. Dramsdahl E, Gundersen Storla D, Harari M. Multidisciplinary Biopsychosocial Program for Chronic Musculoskeletal Pain at the Dead Sea. Isr Med Assoc J. 2019;21(4):255-9 Available from: http://www.ncbi.nlm.nih.gov/pubmed/31 032567. [cited 2019 Oct 3].

95. Mikkelsson M. One year outcome of preadolescents with fibromyalgia. J Rheumatol. 1999;26(3):674-82 Available from: http://www.ncbi.nlm.nih.gov/ pubmed/10090181.

96. Siegel DM, Janeway D, Baum J. Fibromyalgia syndrome in children and adolescents: clinical features at presentation and status at follow-up. Pediatrics. 1998;101(3):377-82 Available from: http://pediatrics.aappublica tions.org/lookup/doi/10.1542/peds.101.3.377.

97. Buskila D, Neumann L, Hershman E, Gedalia A, Press J, Sukenik S. Fibromyalgia syndrome in children--an outcome study. J Rheumatol. 1995; 22(3):525-8 Available from: http://www.ncbi.nlm.nih.gov/pubmed/7783074

98. Hassett AL, Hilliard PE, Goesling J, Clauw DJ, Harte SE, Brummett CM. Reports of chronic pain in childhood and adolescence among patients at a tertiary care pain clinic. J Pain. 2013;14(11):1390-7 Available from: http:// www.ncbi.nlm.nih.gov/pubmed/24021576.

99. Kashikar-Zuck S, King C, Ting TV, Arnold LM. Juvenile fibromyalgia: different from the adult chronic pain syndrome? Curr Rheumatol Rep. 2016;18(4):19 Available from: http://www.ncbi.nlm.nih.gov/pubmed/26984803.

100. Connelly M, Hoffart C, Schikler K, Boneparth A, Weiss JE. A84: changes over time in symptoms and treatment of juvenile primary fibromyalgia syndrome. Arthritis Rheumatol. 2014;66:S117. Available from:. https://doi. org/10.1002/art.38500.

101. Kashikar-Zuck S, Parkins IS, Ting TV, Verkamp E, Lynch-Jordan A, Passo M, et al. Controlled follow-up study of physical and psychosocial functioning of adolescents with juvenile primary fibromyalgia syndrome. Rheumatology.
2010;49(11):2204-9 Available from: https://academic.oup.com/rheuma tology/article-lookup/doi/10.1093/rheumatology/keq254.

102. Kashikar-Zuck S, Cunningham N, Sil S, Bromberg MH, Lynch-Jordan AM, Strotman D, Peugh J, Noll J, Ting TV, Powers SW, Lovell DJ, Arnold LM. Long-term outcomes of adolescents with juvenile-onset fibromyalgia in early adulthood. Pediatrics. 2014;133(3):e592-600 Available from: http:// pediatrics.aappublications.org/cgi/doi/10.1542/peds.2013-2220.

103. Weiss JE, Schikler KN, Boneparth AD, Connelly M. Demographic, clinical, and treatment characteristics of the juvenile primary fibromyalgia syndrome cohort enrolled in the Childhood Arthritis and Rheumatology Research Alliance Legacy Registry. Pediatr Rheumatol. 2019;17(1):1-8.

104. Eraso RM, Bradford NJ, Fontenot CN, Espinoza LR, Gedalia A. Fibromyalgia syndrome in young children: onset at age 10 years and younger. Clin Exp Rheumatol. 2007;25(4):639-44 Available from: https://www.ncbi.nlm.nih.gov/ pubmed/17888225.

105. Gedalia A, García CO, Molina JF, Bradford NJ, Espinoza LR. Fibromyalgia syndrome: experience in a pediatric rheumatology clinic. Clin Exp Rheumatol. 2000;18(3):415-9 Available from: http://www.ncbi.nlm.nih.gov/ pubmed/10895386.

106. Kashikar-Zuck S, Cunningham N, Peugh J, Black WR, Nelson S, Lynch-Jordan AM, Pfeiffer M, Tran ST, Ting TV, Arnold LM, Carle A, Noll J, Powers SW, Lovell DJ. Long-term outcomes of adolescents with juvenile-onset fibromyalgia into adulthood and impact of depressive symptoms on functioning over time. Pain. 2019;160(2):433-41. Available from: http:// insights.ovid.com/crossref?an=00006396-201902000-00017. https://doi.org/1 0.1097/j.pain.0000000000001415.

107. Kashikar-Zuck S, Johnston M, Ting TV, Graham BT, Lynch-Jordan AM, Verkamp E, et al. Relationship between school absenteeism and depressive symptoms among adolescents with juvenile fibromyalgia. J Pediatr Psychol. 2010;35(9):996-1004 Available from: https://academic.oup.com/jpepsy/a rticle-lookup/doi/10.1093/jpepsy/jsq020.

108. Kearney CA. School absenteeism and school refusal behavior in youth: a contemporary review. Clin Psychol Rev. 2008;28(3):451-71 Available from: http://www.ncbi.nlm.nih.gov/pubmed/17720288

109. Sil S, Lynch-Jordan A, Ting TV, Peugh J, Noll J, Kashikar-Zuck S. Influence of family environment on long-term psychosocial functioning of adolescents with juvenile fibromyalgia. Arthritis Care Res (Hoboken). 2013;65(6):903-9. Available from:. https://doi.org/10.1002/acr.21921.

110. Gmuca S, Xiao R, Urquhart A, Weiss PF, Gillham JE, Ginsburg KR, et al. The role of patient and parental resilience in adolescents with chronic musculoskeletal pain. J Pediatr. 2019;210:118-126.e2 Available from: https:// linkinghub.elsevier.com/retrieve/pii/S0022347619302938.

111. Lynch-Jordan AM, Sil S, Bromberg M, Ting TV, Kashikar-Zuck S. Crosssectional study of young adults diagnosed with juvenile fibromyalgia: social support and its impact on functioning and mood. J Adolesc Heal. 2015; 57(5):482-7 Available from: https://linkinghub.elsevier.com/retrieve/pii/S1 054139X15002955

\section{Publisher's Note}

Springer Nature remains neutral with regard to jurisdictional claims in published maps and institutional affiliations.

Ready to submit your research? Choose BMC and benefit from:

- fast, convenient online submission

- thorough peer review by experienced researchers in your field

- rapid publication on acceptance

- support for research data, including large and complex data types

- gold Open Access which fosters wider collaboration and increased citations

- maximum visibility for your research: over $100 \mathrm{M}$ website views per year

At BMC, research is always in progress.

Learn more biomedcentral.com/submission 